Anna-Maria

Giournta

$1,2 \cdot \mathrm{A}, \mathrm{B}, \mathrm{C}, \mathrm{D}, \mathrm{E}, \mathrm{F}$

Victoria Alikari (D)

$3 \cdot \mathrm{C}, \mathrm{D}, \mathrm{E}, \mathrm{F}$

Charalampos Platis

$4 \cdot \mathrm{A}, \mathrm{C}$
Georgia

Oikonomopoulou

$5,6 \cdot \mathrm{A}, \mathrm{B}$

Dimitrios Alefragkis

$7 \cdot \mathrm{D}, \mathrm{E}, \mathrm{F}$

Paraskevi Theofilou

$2,8 \cdot \mathrm{A}, \mathrm{C}, \mathrm{F}$

\title{
Assessing the quality of life and depression among patients with heart failure and heart attack
}

BACKGROUND

Health-related quality and of life and depression are major issues among patients with heart diseases. The aim of the current study was to assess the levels of quality of life and depression among patients with heart failure and heart attack as well as the correlation between these domains and the differences in both categories.

\section{PARTICIPANTS AND PROCEDURE}

In this cross-sectional study the following tools were used: a) the Missoula-VITAS Quality of Life Index (MVQoLI-15), which examines 5 domains of quality of life, and b) the Center for Epidemiological Studies Depression Scale (CES-D), which measures depression among patients. Finally, a questionnaire about sociodemographic elements was completed by the patients. Data were analyzed through IBM Statistics SPSS 20.0. The statistical level was set at $0.05 \%$.

\section{RESULTS}

The mean value of CES-D Total and MVQoLI-15 were higher for the patients suffering from heart failure than those suffering from a heart attack. However, the dimensions of MVQoLI-15 Interpersonal Relationships, Well-Being and Transcendence were lower for heart failure patients compared to the levels of the patients suffering from a heart attack. According to the Pearson $r$ test, there was a statistically significant negative correlation between the quality of life and depression $(p=.001)$ in the overall sample.

\section{CONCLUSIONS}

Patients with heart failure experience more depression and lower quality of life than heart attack patients.

KEY WORDS

quality of life; depression; heart failure; heart attack

ORganization - 1: Department of Psychology, University of Central Lancashire, Preston, UK · 2: College for Humanistic Sciences - ICPS, Athens, Greece · 3: Department of Nursing, University of West Attica, Athens, Greece · 4: National Centre of Public Administration \& Local Government, Athens, Greece · 5: European Association of Hospital Managers (EAHM), Bertrange, Luxemburg · 6: Hellenic Health Services Management Association (HHSMA), Athens, Greece · 7: Errikos Ntynan Hospital Center, Athens, Greece · 8: General Direction of Health Services, Ministry of Health, Athens, Greece

authors' Contributions - A: Study design - B: Data collection · C: Statistical analysis - D: Data interpretation .

E: Manuscript preparation · F: Literature search · G: Funds collection

CORRESPONDING AUthor - Victoria Alikari, Ph.D., Department of Nursing, University of West Attica, 28 Spiridonos Str., 12243 Egaleo, Athens, Greece, e-mail: vicalikari@gmail.com

to Cite this ARTICle - Giournta, A. M., Alikari, V., Platis, C., Oikonomopoulou, G., Alefragkis, D., \& Theofilou, P. (2020).

Assessing the quality of life and depression among patients with heart failure and heart attack. Health Psychology

Report, 8(3), 211-218. https://doi.org/10.5114/hpr.2020.95910

RECEIVED 07.04.2020 • REVIEWED 14.04.2020 • ACCEPTED 10.05.2020 • PUBLISHED 01.06.2020 


\section{BACKGROUND}

People who suffer from heart failure have diverse physical and emotional symptoms such as shortness of breath, fatigue, edema, sleeping difficulties, depression, and chest pain (Alpert, Smith, Hummel, \& Hummel, 2017; DeVon et al., 2017). These symptoms decrease patients' daily physical and social activities as a result of poor quality of life (QoL) (Dunlay et al., 2015). Poor QoL is associated with high rates of hospitalization and mortality (Bundgaard et al., 2020). There are heart failure symptoms and limitations to patients' daily life but they have a positive attitude towards physical, psychological, and social status as well as their behavior. Juenger et al. (2002) established that in congestive heart failure, QoL decreases as New York Heart Association (NYHA) functional class worsens. Though the NYHA functional class is the most dominant predictor among the somatic variables studied, the major determinants of reduced QoL remain unknown (Juenger et al., 2002).

As far as heart attack is concerned, patients who are at working age have the worst QoL. Impaired quality of life is reported by patients unfit for work, those with angina and dyspnoea, patients with coexistent lung disease, and those with anxiety and sleep disturbances (Brown, 2000). Furthermore, according to Höfer, Lim, Guyatt, and Oldridge (2004) the most repeated and significant problem is in the domains of symptoms, restriction, confidence, self-esteem, and emotions. General self-efficacy is positively related to physical and mental QoL two years after the heart attack. For patients with cardiac illness, there is a correlation between self-efficacy and quality of life (Banik, Schwarzer, Knoll, Czekierda, \& Luszczynska, 2018; Barham, Ibraheem, \& Zyoud, 2019). Of course, there are correlations with other aspects such as fatigue, disturbed sleep, self-efficacy, and QoL. Hoekstra et al. (2013) inform us that poor QoL predicts higher mortality in patients with heart failure. This study was the first in this specific domain with a large sample $(N=661)$, where the effect of QoL on mortality was adjusted for levels of brain natriuretic peptide, a widely accepted marker for disease severity and a prognostic tool to predict mortality.

Depression is higher in hospitalized heart failure patients than in stabilized outpatients. Indeed, the assessment of depression in heart failure outpatients is more reliable because symptoms of heart failure are more stable in this phase. Therefore, evaluation and treatment of depression should be started at the diagnosis of heart failure and continued throughout the course of the disease because the level of depression is frequently altered, due to the involvement of other factors. Studies have suggested a worse outcome in heart failure patients with depression across a broad range of events including mortality, healthcare use, and associated clinical conditions. Depression was found to be an independent risk factor for mortality in heart failure, and this persists independently of NYHA class. Three predictors for depression in congestive heart failure hospitalized patients have been identified: functional impairment, the severity of illness, and comorbid psychiatric disorder (Lefteriotis, 2013; Mbakwem, Aina, \& Amadi, 2016; Kourkouta et al., 2015; Hiriscau \& Bodolea, 2019). Joekes, Van Elderen, and Schreurs (2007) found that general selfefficacy was positively related to physical and mental QoL two years after a heart attack.

Treatment of chronic diseases such as heart failure and coronary artery disease aims not only at the improvement of prognosis and relief of symptoms but also at the improvement of QoL, which is decreased in these patients (Unsar, Sut, \& Durna, 2007). The restriction of their usual activities due to the development and worsening of symptoms (dyspnea, angina, fatigue) as well as the increased incidence of rehospitalization, impacts negatively their QoL. In these patients, their daily activity is restricted as well as their social interaction since symptomatic patients with heart failure and/or coronary artery disease (especially in advanced stage) confine their activity to home because of their symptoms or because of the fear to reveal symptoms. Thus, the QoL is considered nowadays at least as important as symptoms and has been recognized as an important target of therapy. Also, health care interventions which aim to control heart failure and coronary heart disease are assessed (Huffman, Adams, \& Celano, 2018).

Many studies on the quality of life in patients with heart failure and a heart attack have been performed. The outcomes are so interesting and some of them were mentioned. Based on the above, the aim of the present study was to investigate 1) the QoL among patients with heart failure and a heart attack, 2) depression among patients with heart failure and a heart attack as well as 3) correlation between these two variables (quality of life and depression) among these groups of patients. Moreover, there is a gap in the bibliography in these specific aspects, as there are no articles related to these patients, so there was a challenge to investigate these domains together. Specifically, our main hypotheses are the following: 1) patients with heart failure will present higher levels of depression compared to those with a heart attack, 2) patients with heart failure will present lower QoL than patients with a heart attack and 3) depression is correlated with overall QoL in the total sample.

\section{PARTICIPANTS AND PROCEDURE}

\section{PARTICIPANTS}

In this cross-sectional study, 60 participants (30 with heart failure and 30 with a heart attack) were recruited from Tzaneion General Hospital of Piraeus (Attica, 
Greece). Selection criteria included i) age $>18$ years old, ii) clinical diagnosis: heart failure stage I-II, and heart attack. Exclusion criteria were: heart failure stage III and IV, difficulty in communication, and psychiatric problems. Patients were stratified so that the two groups had the same demographic and clinical characteristics.

\section{MEASURES}

In the current study, two instruments were used:

The Missoula-VITAS Quality of Life Index (MVQoLI-15; Byock \& Merriman, 1998) compiles information about QoL during an advanced illness. The specific questionnaire can be used in a variety of health care settings such as hospitals, hospices, home health, longterm care, outpatient palliative care, and pre-hospice programs (Byock, 1996). The MVQoLI-15 examines 5 dimensions or domains of QoL: Symptoms, Function, Interpersonal, Well-Being, and Transcendence. Within each dimension, three kinds of information are gathered from respondents in order to illuminate their overall experience: Assessment (A) - the subjective measurement of actual status or circumstance; Satisfaction (S) - the degree of acceptance or mastery of actual circumstance; Importance (I) - the degree to which a dimension has an impact on overall QoL. The items are scored as follows: Assessment $(-2$ to +2$)$, Satisfaction $(-4$ to +4$)$ Importance ( 1 to 5$)$ where: (Assessment + Satisfaction $) \times$ Importance $=$ QoL in each dimension. Negative dimensions diminish QoL, positive dimensions increase QoL. In this study, the Greek version of MVQoLI-15 was translated by Theofilou, Kapsalis, and Panagiotaki (2012) with very good psychometric properties (Cronbach's $\alpha$ index: .74) (Theofilou, Aroni, Ralli, Gouzou, \& Zyga, 2013). It has been used in many studies in Greece (Zyga et al., 2015; Alikari et al., 2019). The reliability of the scale was investigated in this study (Cronbach's $\alpha$ : .78).

The Center for Epidemiological Studies Depression Scale (CES-D) was used for the assessment of depression. This questionnaire was designed for research for the general population; for this reason, it is shortly extended. This 20 -item scale asks subjects to estimate the frequency of their experienced symptoms related to depression during the last week including restless sleep, poor appetite, and feeling lonely. Responses range from 0 to 3 for each item $(0$ - rarely or never, 1 - some or little of the time, 2 - moderately or much of the time, 3 - most or almost all the time) and scores range from 0 to 60 (Radloff, 1977). There are cutoff scores (16 or higher), that help to identify people at risk of clinical depression. In this study, the Greek version of the CES-D was used (Fountoulakis et al., 2001). It has been used for a variety of other studies (Fountoulakis et al., 2003; Mougias et al., 2015). The reliability was tested in this study (Cronbach's $\alpha:$.88)
Finally, the sociodemographic elements were recorded. The study took place between February 2018 and April 2018.

\section{ETHICAL CONSIDERATIONS}

Participants signed the consent form and were informed about the anonymity of the data, that the data would be used for research purposes only and that they had the right to refuse or discontinue participation, according to the ethical standards of the Helsinki Declaration of 1983. Ethical permission for the research was obtained from the Scientific Committee of the Tzaneion Hospital.

\section{STATISTICAL ANALYSIS}

Analyses such as standard deviations, means including maximum and minimum values and statistical significance were performed. As far as descriptive statistics is concerned, frequencies were determined for each variable. The normality of variables was examined in order to determine any statistical significance in these variables. Consequently, statistically significant differences occur only for the variable CES-D Total that expresses the depression level of the participants. The variables CES-D Total, Symptoms, Function, Interpersonal, Well-being, and Transcendence do not follow the normal distribution. On the other hand, the variable MVQoLI-15 Total is normally distributed $(p>.05)$. This means that for the variables CES-D Total, Symptoms, Function, Interpersonal, Wellbeing, and Transcendence non-parametric tests were used, while for the variable MVQoLI-15 Total parametric tests were used. The reliability of both scales was investigated through the Cronbach's $\alpha$ index. In order to test the differences between the two study groups, the Mann-Whitney test was carried out. Finally, for the correlation of CES-D Total and MVQoLI-15 Total, the Pearson test was performed. Data were analyzed through IBM Statistics SPSS 20.0. The statistical level was set at $0.05 \%$.

\section{RESULTS}

\section{DEMOGRAPHICS}

The basic demographic characteristics of the sample are presented. Most patients were male, married and the mean value of the participants' age was 67.24 years (Table 1).

Table 2 summarizes the main descriptive results for (i) the sample suffering from heart failure and (ii) the sample suffering from a heart attack. The mean value of CES-D Total is higher for the patients suffering from
Quality of life and depression in cardiac diseases 
Table 1

Participants' demographic and clinical characteristics

\begin{tabular}{|c|c|c|c|c|}
\hline & \multicolumn{2}{|c|}{ Heart failure $(n=30)$} & \multicolumn{2}{|c|}{ Heart attack $(n=30)$} \\
\hline & Frequency & $\%$ & Frequency & $\%$ \\
\hline \multicolumn{5}{|l|}{ Gender } \\
\hline Male & 15 & 50.00 & 15 & 50.00 \\
\hline Female & 15 & 50.00 & 15 & 50.00 \\
\hline \multicolumn{5}{|l|}{ Marital status } \\
\hline Unmarried & 3 & 10.00 & 2 & 6.66 \\
\hline Married & 24 & 80.00 & 25 & 83.33 \\
\hline Divorced & 2 & 6.67 & 2 & 6.67 \\
\hline Widowed & 1 & 3.33 & 1 & 3.33 \\
\hline \multicolumn{5}{|l|}{ Educational level } \\
\hline Primary education & 3 & 10.00 & 5 & 16.66 \\
\hline Secondary education & 15 & 50.00 & 14 & 46.67 \\
\hline \multirow[t]{2}{*}{ University } & 12 & 40.00 & 11 & 36.67 \\
\hline & $M(S D)$ & Min-Max & $M(S D)$ & Min-Max \\
\hline Age (years) & $67.20(12.60)$ & $36-70$ & $67.00(11.90)$ & $35-69$ \\
\hline Weight (kg) & $82.90(16.80)$ & $51-140$ & $82.70(17.00)$ & $55-135$ \\
\hline Height $(\mathrm{cm})$ & $170.10(7.70)$ & $156-187$ & $169.10(7.50)$ & $157-186$ \\
\hline Years from diagnosis & $5.51(8.00)$ & $1-40$ & $4.09(5.54)$ & $1-20$ \\
\hline
\end{tabular}

Table 2

Descriptive statistics for MVQoLI-15 and CES-D

\begin{tabular}{lcccc}
\hline & Min & Max & M & $S D$ \\
\hline CES-D Total & Heart failure & & \\
Symptoms & 5.00 & 38.00 & 18.60 & 8.53 \\
Function & -20.00 & 20.00 & 10.05 & 9.44 \\
Interpersonal & -25.00 & 20.00 & 3.42 & 12.15 \\
Well-Being & -16.00 & 25.00 & 9.97 & 12.43 \\
Transcendent & -110.00 & 16.00 & -11.11 & 20.92 \\
MVQoLI-15 Total & -20.00 & 30.00 & 10.82 & 13.45 \\
\hline & -50.50 & 75.50 & 28.42 & 30.04 \\
\hline CES-D Total & Heart attack & & 14.37 & 8.38 \\
Symptoms & 1.00 & 34.00 & 10.45 & 8.27 \\
Function & -16.00 & 30.00 & 1.60 & 11.83 \\
Interpersonal & -30.00 & 20.00 & 14.68 & 10.13 \\
Well-being & -10.00 & 30.00 & -5.25 & 13.96 \\
Transcendent & -30.00 & 20.00 & 15.80 & 10.45 \\
MVQoLI-15 Total & -16.00 & 30.00 & 38.06 & 21.97 \\
\hline Note-MVQol-15-Missur & -4.60 & 88.50 & &
\end{tabular}

Note. MVQoLI-15 - Missoula-VITAS Quality of Life Index; CES-D - Center for Epidemiological Studies Depression Scale. 
heart failure. Moreover, the QoL for the patients suffering from heart failure is higher regarding Function, lower regarding Interpersonal Relationships, WellBeing, Transcendence, and about the same regarding Symptoms, compared to the levels of the patients suffering from a heart attack. Regarding the CES-D, the minimum value is 1 , which means no depression at all, and the maximum is 38 , which indicates a very depressed person, leading to a range of 37.

In order to verify the differences between the two groups, the Mann-Whitney test was carried out (Table 3).

As shown in Table 4, statistically significant differences occur only for the variable CES-D Total, which expresses the depression level of the participants $(p<.05)$. More specifically, the depression levels are higher for the patients suffering from heart failure, compared to those suffering from a heart attack. For all the other variables, the differences are not statistically significant $(p>.05$ for all cases).
As far as the MVQoLI-15 Total is concerned, the variable followed the normal distribution. The $t$-test $(t=-1.53)$ showed that although we have a mean difference equal to -9.64 (mean for MVQoLI-15 $=28.42$, mean for CES-D = 38.06) between the two groups of participants, that difference is not statistically significant $(p>.05)$.

Finally, for the correlation of CES-D Total with the MVQoLI-15 Total variables, both Pearson $r$ and Spearman rho tests were carried out. As shown in Table 5, according to the Pearson $r$ test, there is a statistically significant negative correlation between the two variables $(p=.001)$.

\section{DISCUSSION}

The main focus of the present study was to examine QoL in patients with heart failure and heart attack and investigate the possible differences. The results

Table 3

Differences in levels of QoL and depression between the two groups $(N=60)$

\begin{tabular}{llcc}
\hline & Disease & Mean rank & Sum of ranks \\
\hline CES-D Total & Heart failure & 40.40 & 1414.00 \\
Symptoms & Heart attack & 30.60 & 1071.00 \\
\multirow{2}{*}{ Function } & Heart failure & 36.13 & 1264.50 \\
& Heart attack & 34.87 & 1220.50 \\
Interpersonal & Heart failure & 37.24 & 1303.50 \\
\multirow{2}{*}{ Well-being } & Heart attack & 33.76 & 1181.50 \\
& Heart failure & 31.34 & 1097.00 \\
Transcendence & Heart attack & 39.66 & 1388.00 \\
& Heart failure & 32.63 & 1142.00 \\
& Heart attack & 38.37 & 1343.00
\end{tabular}

Note. Non-parametric tests - Mann-Whitney test: ranks; QoL - quality of life; CES-D - Center for Epidemiological Studies Depression Scale.

Table 4

Differences between the dimensions

\begin{tabular}{lcccccc}
\hline & $\begin{array}{c}\text { CES-D } \\
\text { Total }\end{array}$ & Symptoms & Function & $\begin{array}{c}\text { Inter- } \\
\text { personal }\end{array}$ & Well-being & $\begin{array}{c}\text { Transcen- } \\
\text { dence }\end{array}$ \\
\hline Mann-Whitney $U$ & 441.00 & 590.50 & 551.50 & 467.00 & 512.00 & 490.50 \\
Wilcoxon W & 1071.00 & 1220.50 & 1181.50 & 1097.00 & 1142.00 & 1120.50 \\
$Z$ & -2.02 & -0.26 & -0.72 & -1.74 & -1.19 & -1.45 \\
$p$ & .044 & .795 & .470 & .082 & .236 & .146 \\
\hline
\end{tabular}

Note. Grouping variable: disease; non-parametric tests - Mann-Whitney test; CES-D - Center for Epidemiological Studies Depression Scale. 
Table 5

Correlation between CES-D Total and MVQoLI-15 Total

\begin{tabular}{lccc}
\hline & & $\begin{array}{c}\text { CES-D } \\
\text { Total }\end{array}$ & $\begin{array}{c}\text { MVQoLI-15 } \\
\text { Total }\end{array}$ \\
\hline $\begin{array}{l}\text { CES-D } \\
\text { Total }\end{array}$ & $\begin{array}{c}\text { Pearson } \\
\text { correlation }\end{array}$ & 1 & -.39 \\
& $p$ & & .001 \\
\hline
\end{tabular}

Anna-Maria
Giournta,
Victoria Alikari,
Charalampos
Platis, Georgia
Oikonomopoulou,
Dimitrios
Alefragkis,
Paraskevi
Theofilou

provide evidence that although the sense of wellbeing is low accompanied by a low level of daily activities (function) in the overall population, parameters such as QoL, Interpersonal Relationships, Symptoms, and Transcendence (sense of life meaning) are above the average. Low sense of wellbeing and function are common in patients with heart failure and/or a heart attack. Several studies (Saran, Puri, \& Agarwal, 2012; Juenger et al., 2002) assessed this issue and found that the symptoms that accompanied these diseases as well as the global limitation of their activity affected negatively those parameters. In a prospective study (Herlitz et al., 1999) the authors found that in these patients, wellbeing and quality of life were impaired, and the presence of supervening diseases, such as diabetes mellitus and chronic obstructive pulmonary disease, aggravated further their quality of life and the sense of wellbeing. Similarly, in another prospective study among coronary heart disease patients (Lukkarinen \& Hentinen, 1997), the authors found that the quality of life of those patients was significantly poorer in all the six dimensions of physical mobility, pain, sleep, energy, emotional reactions, and social isolation before treatment. Likewise, in patients with heart failure, well-being, and quality of life are compromised. In a prospective study, Juenger et al. (2002) concluded that the QoL and wellbeing were significantly related to functional status and precisely to NYHA class. Patients with higher NYHA class presented a worse sense of wellbeing and quality of life.

In addition, we found that the depression levels were higher in patients suffering from heart failure than in those suffering from a heart attack. The complexity of heart failure, as well as the plethora of symptoms, and the increased incidence of rehospitalization due to heart failure decompensation, may explain these results. Although the groups of patients (with coronary heart disease and heart failure) require a close follow-up and monitoring, patients with heart failure present more often progressive or acute decompensation due to the nature of this syndrome. Current guidelines recommend, for those patients, very close monitoring with a 'seamless' system of care, embracing both the community and hospital, to ensure that the management of every patient is optimal (McMurray et al., 2012). In fact, these patients need to be monitored daily in order to assess symptoms, weight, fluid intake and output and to prevent consequently or diagnose early a decompensation (McMurray et al., 2012). In a prospective study that assessed the prevalence of depression in patients with or without heart failure who were hospitalized with a heart attack, major depression was observed in $43 \%$ in the heart failure group compared with $36 \%$ in the non-heart failure group (Powel et al., 2005). Likewise, in another prospective study among patients after a heart attack, patients with symptoms of angina reacted to the illness with anxiety more than depression, whereas patients with heart failure with dyspnea reacted to the illness with depressive symptoms more than anxiety (Moryś, Bellwon, Höfer, Rynkiewicz, \& Gruchała, 2016).

Nowadays, it is established that from the societal and social points of view, the patients' quality of life is even more important than the objective medical outcome. In a prospective study that enrolled 99 patients with advanced heart failure, heart failure patients expressed meaningful preferences about quality of life with respect to the length of life (Lewis et al., 2001).

\section{LIMITATIONS OF THE STUDY}

Since the sample size of our study is small, it is not possible to generalize these results for all patients with heart failure and/or a heart attack. However, this single-center study is in line with other multicenter studies assessing this issue. In addition, the questionnaires were completed during the course of treatment. Thus, the presence of other patients and medical staff may influence the objectivity of the responses. However, this is a common limitation of such studies when the results are based on the subjective perception of patients.

\section{CONCLUSIONS}

According to the findings of this study, patients with heart failure present higher levels of depression and lower quality of life than patients with a heart attack. However, some dimensions of QoL are higher for heart failure patients. Also, depression is correlated with the quality of life in the overall sample. Thus, we suggest the creation of interdisciplinary teams that also involve nurses in order to amplify and expand health care management, assessing not only the medicinal side of care but also including broader 
aspects of physical, mental, and social health. We also suggest the creation of specialized nurse personnel in heart failure and/or coronary artery disease in order to better perceive and understand not only symptoms but also the nature of the disease, improving health care management.

Health psychologists use a bio-psychosocial guide in recognizing health practices. This method centers on understanding wellness to be the result not only of biological processes (hormonal and endocrine functioning) but also of mental processes such as approaches toward health and how people cope with stress in their lives.

\section{ACKNOWLEDGMENTS}

We thank patients for their participation and the Scientific Council of Tzaneion Hospital.

\section{References}

Alikari, V., Tsironi, M., Matziou, V., Tzavella, F., Stathoulis, J., Babatsikou, F., Fradelos, E., \& Zyga, S. (2019). The impact of education on knowledge, adherence and quality of life among patients on haemodialysis. Quality of Life Research, 28, 73-83. https://doi. org/10.1007/s11136-018-1989-y

Alpert, C. M., Smith, M. A., Hummel, S. L., \& Hummel, E. K. (2017). Symptom burden in heart failure: assessment, impact on outcomes, and management. Heart Failure Reviews, 22, 25-39. https://doi. org/10.1007/s10741-016-9581-4

Banik, A., Schwarzer, R., Knoll, N., Czekierda, K., \& Luszczynska, A. (2018). Self-efficacy and quality of life among people with cardiovascular diseases: a meta-analysis. Rehabilitation Psychology, 63, 295-312. https://doi.org/10.1037/rep0000199

Barham, A., Ibraheem, R., \& Zyoud, S. H. (2019). Cardiac self-efficacy and quality of life in patients with coronary heart disease: a cross-sectional study from Palestine. BMC Cardiovascular Disorders, 19, article 290. https://doi.org/10.1186/s12872-019-01281-7

Brown, R. I. (2000). Quality of life: Challenges and confrontation. In K. D. Keith \& R. L. Schalock (Eds.), Cross-cultural perspectives on quality of life (pp. 347-362). Washington, DC: American Association on Mental Retardation

Bundgaard, J. S., Thune, J. J., Gislason, G., Fosbøl, E. L., Torp-Pedersen, C., Aagaard, D., Nielsen, J. C., Haarbo, J., Thøgersen, A. M., Videbæk, L., Jensen, G., Olesen, L. L., Kristensen, S. L., Pedersen, S. S., Køber, L., \& Mogensen, U. M. (2020). Quality of life and the associated risk of all-cause mortality in nonischemic heart failure. International Journal of Cardiology, 305, 92-98. https://doi.org/10.1016/ j.ijcard.2020.02.008
Byock, I. R. (1996). The nature of suffering and the nature of opportunity at the end of life. Clinics in Geriatric Medicine, 12, 237-252.

Byock, I. R., \& Merriman, M. P. (1998). Measuring quality of life for patients with terminal illness: The Missoula-VITAS Quality of Life Index. Palliative Medicine, 12, 231-244. https://doi.org/10.1191/ 026921698670234618

DeVon, H. A., Vuckovic, K., Ryan, C. J., Barnason, S., Zerwic, J. J., Pozehl, B., Schulz, P., Seo, Y., \& Zimmerman, L. (2017). Systematic review of symptom clusters in cardiovascular disease. European Journal of Cardiovascular Nursing, 16, 6-17. https://doi. org/10.1177/1474515116642594

Dunlay, S. M., Manemann, S. M., Chamberlain, A. M., Cheville, A. L., Jiang, R., Weston, S. A., \& Roger, V. L. (2015). Activities of daily living and outcomes in heart failure. Circulation Heart Failure, 8, 261-267. https://doi.org/10.1161/CIRCHEARTFAILURE. 114.001542

Fountoulakis, K. N., lacovides, A., Kleanthous, S., Samolis, S., Gougoulias, K., Kaprinis, G. S., \& Bech, P. (2003). The Greek translation of the symptoms rating scale for depression and anxiety: preliminary results of the validation study. BMC Psychiatry, 3, article 21. https://doi.org/10.1186/1471-244X-3-21

Fountoulakis, K., lacovides, A., Kleanthous, S., Samolis, S., Kaprinis, S. G., Sitzoglou, K., Kaprinis, G. S., \& Bech, P. (2001). Reliability, validity and psychometric properties of the Greek translation of the Center for Epidemiological Studies-Depression (CES-D) Scale. BMC Psychiatry, 1, article 3. https:// doi.org/10.1186/1471-244x-1-3

Herlitz, J., Wiklund, I., Caidahl, K., Karlson, B. W., Sjöland, H., Hartford, M., Haglid, M., \& Karlsson, T. (1999). Determinants of an impaired quality of life five years after coronary artery bypass surgery. Heart, 81, 342-346. https://doi.org/10.1136/ hrt.81.4.342

Hiriscau, E. I., \& Bodolea, C. (2019). The role of depression and anxiety in frail patients with heart failure. Diseases, 7, 45. https://doi.org/10.3390/diseases 7020045

Hoekstra, T., Jaarsma, T., van Veldhuisen, D. J., Hillege, H. L., Sanderman, R., \& Lesman-Leegte, I. (2013). Quality of life and survival in patients with heart failure. European Journal of Heart Failure, 15, 94-102. https://doi.org/10.1093/eurjhf/hfs 148

Höfer, S., Lim, L., Guyatt, G., \& Oldridge, N. (2004). The MacNew Heart Disease health-related quality of life instrument: a summary. Health and Quality of Life Outcomes, 2, article 3. https://doi. org/10.1186/1477-7525-2-3

Huffman, J. C., Adams, C. N., \& Celano, C. M. (2018). Collaborative care and related interventions in patients with heart disease: an update and new directions. Psychosomatics, 59, 1-18. https://doi. org/10.1016/j.psym.2017.09.003
Quality of life and depression in cardiac diseases 
Joekes, K., Van Elderen, T., \& Schreurs, K. (2007). Selfefficacy and overprotection are related to quality of life, psychological well-being and self-management in cardiac patients. Journal of Health Psychology, 12, 4-16. https://doi.org/10.1177/1359105306069096

Juenger, J., Schellberg, D., Kraemer, S., Haunstetter, A., Zugck, C., Herzog, W., \& Haass, M. (2002). Health related quality of life in patients with congestive heart failure: Comparison with other chronic diseases and relation to functional variables. Heart, 87, 235-241. https://doi.org/10.1136/heart.87.3.235

Anna-Maria

Giournta,

Victoria Alikari,

Charalampos

Platis, Georgia

Oikonomopoulou,

Dimitrios

Alefragkis,

Paraskevi

Theofilou

Kourkouta, L., Papathanasiou, V., Koukourikos, K., Kleisiaris, C., Fradelos, C. E., \& Tsaloglidou, A. (2015). Circulatory system's diseases in the elderly. Journal of Pharmacy and Pharmacology, 3, 591-595. https://doi.org/10.17265/2328-2150/2015.12.006

Lefteriotis, C. (2013). Depression in heart failure patients. Health Science Journal, 7, 349-355.

Lewis, E. F., Johnson, P. A., Johnson, W., Collins, C. Griffin, L., \& Stevenson, L. W. (2001). Preferences for quality of life or survival expressed by patients with heart failure. Journal of Heart \& Lung Transplantation, 20, 1016-1024. https://doi.org/10.1016/ s1053-2498(01)00298-4

Lukkarinen, H., \& Hentinen, M. (1997). Assessment of quality of life with the Nottingham Health Profile among patients with coronary heart disease. Journal of Advanced Nursing, 26, 73-84. https://doi. org/10.1046/j.1365-2648.1997.1997026073.x

Mbakwem, A., Aina, F., \& Amadi, C. (2016). Depression in patients with heart failure: Is enough being done? Cardiac Failure Review, 2, 110-112. https:// doi.org/10.15420/cfr.2016:21:1

McMurray, J. J., Adamopoulos, S., Anker, S. D., Auricchio, A., Böhm, M., Dickstein, K., ... ESC Committee for Practice Guidelines (2012). ESC guidelines for the diagnosis and treatment of acute and chronic heart failure 2012: The task force for the diagnosis and treatment of acute and chronic heart failure 2012 of the European Society of Cardiology. European Heart Journal, 33, 1787-1847. https://doi. org/10.1093/eurheartj/ehs104

Moryś, J. M., Bellwon, J., Höfer, S., Rynkiewicz, A., \& Gruchała, M. (2016). Quality of life in patients with coronary heart disease after myocardial infarction and with ischemic heart failure. Archives of Medical Science, 12, 326-333. https://doi.org/10.5114/ aoms.2014.47881

Mougias, A. A., Politis, A., Mougias, M. A., Kotrotsou, I., Skapinakis, P., Damigos, D., \& Mavreas, V. G. (2015). The burden of caring for patients with dementia and its predictors. Psychiatriki, 26, 28-37.

Powel, L. H., Catellier, D., Freedland, K. E., Burg, M. M., Woods, S. L., Bittner, V., Calvin, J. E., \& Blumenthal, J. A. (2005). Depression and heart failure in patients with a new myocardial infarction. American Heart Journal, 149, 851-855. https://doi.org/10.1016/ j.ahj.2004.08.007
Radloff, L. S. (1977). The CES-D scale: a self report depression scale for research in the general population. Applied Psychological Measurements, 1, 385401. https://doi.org/10.1177/014662167700100306

Saran, R. K., Puri, A., \& Agarwal, M. (2012). Depression and the heart. Indian Heart Journal, 64, 397401. https://doi.org/10.1016/j.ihj.2012.06.004

Theofilou, P., Aroni, A., Ralli, M., Gouzou, M., \& Zyga, S. (2013). Measuring health: Related quality of life in hemodialysis patients. Psychometric properties of the Missoula-VITAS Quality of Life Index (MVQoLI-15) in Greece. Health Psychology Research, 1, e17. https://doi.org/10.4081/hpr.2013.e17

Theofilou, P., Kapslis, F., \& Panagiotaki, H. (2012). Greek version of MVQoLI-15: Translation and cultural adaptation. International Journal of Caring Sciences, 5, 289-294.

Unsar, S., Sut, N., \& Durna, Z. (2007). Health-related quality of life in patients with coronary artery disease. Journal of Cardiovascular Nursing, 22, 501-507. https://doi.org/10.1097/01.JCN.0000297382.91131.8d

Zyga, S., Alikari, V., Sachlas, A., Stathoulis, J., Aroni, A., Theofilou, P., \& Panoutsopoulos, G. (2015). Management of pain and quality of life in patients with chronic kidney disease undergoing hemodialysis. Pain Management Nursing, 16, 712-720. https://doi. org/10.1016/j.pmn.2015.03.004 